\title{
DETECTION OF „HOTSPOT“ MUTATIONS IN CATALYTIC SUBUNIT OF PHOSPHATIDYLINOSITOL 3-KINASE (PIK3CA) BY ALLELE-SPECIFIC POLYMERASE CHAIN REACTION
}

\author{
Mendelova $\mathrm{A}^{1,2}$, Holubekova $\mathrm{V}^{2}$, Zubor $\mathrm{P}^{1}$, Jezkova $\mathrm{E}^{1,2}$, Gemzova $\mathrm{K}^{2}$, Plank L ${ }^{3}$, \\ Danko $\mathrm{J}^{1}$, Lasabova $\mathrm{Z}^{2}$
}

\begin{abstract}
${ }^{1}$ Department of Obstetrics and Gynecology, Jessenius Faculty of Medicine in Martin, Comenius University in Bratislava, Slovak Republic

${ }^{2}$ Department of Molecular Biology, Jessenius Faculty of Medicine in Martin, Comenius University in Bratislava, Slovak Republic

${ }^{3}$ Department of Pathological Anatomy, Jessenius Faculty of Medicine in Martin, Comenius University in Bratislava, Slovak Republic
\end{abstract}

\begin{abstract}
A b s t r a c t
The phosphatidylinositol 3-kinases (PI3Ks) are a family of proteins involved in the regulation of cell survival, growth, metabolism, and glucose homeostasis. Increased PI3K activity is associated with many cancers. PIK3CA gene (encoding p110, the catalytic subunit of PI3K) is commonly mutated in breast cancer. In our study we focused on the detection of "hotspot" mutations in exons 9 and 20 of the PIK3CA gene in paraffin-embedded tissue of patients with breast cancer. We optimized conditions of allele specific polymerase chain reaction (PCR) and we used direct sequencing to verify our results. Overall, three "hotspot" mutations in PIK3CA gene in paraffin-embadded tissue from breast cancer were detected by allele-specific PCR. All results were verified by direct sequencing of PCR products and we observed 100\% agreement between those two methods. We confirmed that allele-specific PCR assay is low cost method usefull for accurate detection of PIK3CA mutations.
\end{abstract}

Key words: PIK3CA, “hotspots", allele-specific PCR, PI3K pathway

\section{INTRODUCTION}

The phosphatidylinositol 3-kinases (PI3Ks) are heterodimeric lipid kinases composed of regulatory $(85-\mathrm{kDa}, \mathrm{p} 85)$ and catalytic $(110-\mathrm{kDa}, \mathrm{p} 110)$ subunit $(1)$, which are encoded by separate genes and are subject to alternative splicing (2). Primary biochemical function PI3Ks is to phosphorylate the 3-hydroxyl group of phosphoinositides. PI3Ks are grouped into three classes (I-III) with varying structure and substrate preference (3). The $85-\mathrm{kDa}$ subunit lacks PI3K activity and acts as adaptor, coupling the $110-\mathrm{kDa}$ subunit to activated protein tyrosine kinases and generating second messengers by phosphorylating membrane inositol lipids at the D3 position (1). PI3Ks play an important role as regulators of various cellular processes as cellular growth, transformation, adhesion, apoptosis, survival, DNA repair, adhesion and motility through the PI3K/AKT/mTOR signalling pathway $(4,5)$. This pathway is frequently activated by mutations (5). Mutations occur predominantly in the helical and kinase domains of the catalytic subunit, which is encoded by the PIK3CA gene. PIK3CA gene, which is amplified, overexpressed, or mutated in several human malignancies and might have oncogenic activity in humans (6). The vast majority of PIK3CA mutations are clustered at three „hotspot" regions. Two „hotspot" regions are in exon 9 in helical domain (E542K, E545K) and one „hotspot“ mutation is observed in exon 20 in kinase domain (H1047R). Determination somatic mutational status can be provided by various methods, including sequencing and pyrosequencing, we also decided to use allele-specific PCR assay, which is inexpensive and fast diagnostic tool for accurate detection of PIK3CA mutations.

Corresponding a u thor:

Andrea Mendelova, Mgr., Department of Molecular Biology, Jessenius Faculty of Medicine, Comenius University, Martin, Kalinciaka 2, 03861 Vrutky, Slovakia.

Phone: 00421-43-4286517; e-mail: a.mendelova@gmail.com 
Allele-specific polymerase chain reaction (AS-PCR), also known as PCR amplification of specific alleles (PASA) or amplification refractory mutation system (ARMS), is a PCR-based method for detection of any mutation involving single base changes or small deletions. ASPCR is based on the use of sequence-specific PCR primers that allow amplification of test DNA only when the sample contains the target allele. Following an AS-PCR reaction, the presence or absence of PCR product represents the presence or absence of target allele (7).

In the allele-specific PCR approach, one relies on the DNA polymerase to extend a primer only when its 3' end is perfectly complementary to the template. When this condition is met, a PCR product is produced. By determining whether a PCR product is produced or not, one can infer the allele found on the target DNA (8).

The method presented here allows efficient discrimination mutations by allele-specific PCR in a single reaction with standard PCR conditions. A two reverse primers and two forward allele-specific primers with different tails amplify two allele-specific PCR products of different lengths, which are further separated by agarose gel electrophoresis. PCR specificity is improved by the introduction of a destabilizing mismatch within the 3' end of the allelespecific primers.

In our study we focused on the detection of "hotspot" mutations in exons 9 and 20 of the PIK3CA gene in paraffin-embedded tissue of patients with breast cancer. We used two methods; we optimized conditions of allele specific PCR and we used direct sequencing to verify our results.

\section{MATERIALS AND METHODS}

\section{Tumor samples}

Paraffin-embedded tissue sections were obtained from biopsy specimens of breast cancer patients with histological and immunohistochemical characterization of tumor type determined by Department of Pathological Anatomy.

We analyzed 60 DNA samples extracted from archival formalin-fixed paraffin-embadded tissue breast cancer and results of allele-specific PCR were compared to those obtained from direct sequencing.

\section{DNA extraction}

DNA was isolated from paraffin-embadded tissue after deparaffinization in xylen to remove paraffin and washed in absolute and then in 70\% ethanol. Genomic DNA was extracted using DNeasy Blood and Tissue Kit (Qiagen, Germany) according to the manufacturer's instructions. DNA quantity was estimated by UV spectrophotometry and each sample was diluted to final concentration - 20ng of genomic DNA, which was used as a template in allele-specific PCR.

\section{Allele-specific PCR reaction}

For optimization of allele-specific PCR for detection of „hotspot“ mutations in exon 9 of PIK3CA gene we used two samples containing E542K mutation, two samples containing E545K mutation and two wild-type samples, which was determined by Sanger dideoxysequencing. Similarly, two samples containing H1047R mutation and two wild-type samples were used in optimization of PCR reaction conditions for detection of mutations in exon 20 .

PCR reactions were performed in total volume of $25 \mu \mathrm{l}$ using $1.5 \mathrm{mM}$ or $4 \mathrm{mM} \mathrm{MgCl}_{2}$, with $200 \mu \mathrm{M}$ deoxynucleotide triphosphates (dNTPs, Gene Amp dNTP Mix with dTTP, Applied Biosystems, USA), $0.5 \mu \mathrm{M}$ of each primer, $1 \mathrm{U}$ Taq polymerase (FastStart Taq DNA Polymerase, Roche Diagnostics GmbH, Germany) and 20ng of genomic DNA.

The amplification products were separated by electrophoresis on $2 \%$ agarose gel stained with GelRed Nucleic Acid (Biotinum, Inc., USA). PCR products were visualised on UV transilluminator.

The presence of mutations in exon 9 and 20 was verified by direct sequencing of PCR products. After PCR amplification, PCR products were purified by NucleoSpin Extract II kit 
(Macherey-Nagel, Germany) according to the manufacturer's instructions following the cycle sequencing with using forward or reverse primer and BigDye ${ }^{\circledR}$ Terminator v1.1 Cycle Sequencing Kit. Products were analysed in 3500 Genetic Analyzer (Applied Biosystems, USA) and the sequences were compared to the corresponding reference sequence by BLAST program (http://blast.ncbi.nlm.nih.gov/Blast.cgi).

Table 1 Sequences of primers and their annealing temperatures

\begin{tabular}{|l|l|l|l|}
\hline No. & Primer type & Sequence & $\begin{array}{l}\text { Annealing } \\
\text { temperature }\end{array}$ \\
\hline 1. & PIK3CA exon 9 forward & 5 - caatgaattaagggaaaatgaca -3 & $56^{\circ} \mathrm{C}$ \\
\hline 2. & PIK3CA exon 9 forward WT & 5 - tgaaatcactgagcaggagaa-3 & $56^{\circ} \mathrm{C}$ \\
\hline 3. & PIK3CA „E542K“ & 5 - ctttctcctgctcagtgattct -3 & $60^{\circ} \mathrm{C}$ \\
\hline 4. & PIK3CA „E545K“ & 5 - actccatagaaatctttctcctgatt -3 & $68^{\circ} \mathrm{C}$ \\
\hline 5. & PIK3CA exon 9 reverse & 5 - tatttattccaataggtatggta -3 & $54^{\circ} \mathrm{C}$ \\
\hline 6. & PIK3CA exon 20 forward & 5 - ccctagccttagataaaactgagcaa -3 & $70^{\circ} \mathrm{C}$ \\
\hline 7. & PIK3CA exon 20 forward WT & 5 - atgcacatcatggtggctgg -3 & $58^{\circ} \mathrm{C}$ \\
\hline 8. & PIK3CA „H1047R“ & 5 - tgttgtccagccaccatgcc -3 & $60^{\circ} \mathrm{C}$ \\
\hline 9. & PIK3CA exon 20 reverse & 5 - taacagtgcagtgtggaatcca -3 & $60^{\circ} \mathrm{C}$ \\
\hline
\end{tabular}

\section{Allele-specific PCR for detection of E542K mutation in exon 9 of PIK3CA gene}

PCR amplification was performed in two separate tubes for amplification of wild-type and mutant variant. Primer sequences used in allele-specific PCRs are shown in Table 1. The first tube was containing primers No.1 and No.3 specific to mutant allele and the second tube was containing primers No.2 and No.5 specific to wild type allele. Both PCR reactions were running at optimal conditions of $1.5 \mathrm{mM} \mathrm{MgCl}_{2}$. Thermal cycling protocol included steps as initial denaturation at $95^{\circ} \mathrm{C}$ for 10 minutes, followed by 35 cycles of amplification: $95^{\circ} \mathrm{C}$ for $30 \mathrm{~s}, 60^{\circ} \mathrm{C}$ (for mutant allele) and $56^{\circ} \mathrm{C}$ (for wild-type allele) during $45 \mathrm{~s}$ and $72^{\circ} \mathrm{C}$ for $1 \mathrm{~min}$. The final extension was performed at $72^{\circ} \mathrm{C}$ for 10 minutes.

\section{Allele specific PCR to detect E545K mutation in exon 9 PIK3CA gene}

Similarly as the previous PCR reaction, amplification was performed in two separate tubes for wild-type and mutant allele. The first tube was containing primers No.1 and No.4 (Table 1) specific to mutant allele and the second tube was containing primers No.2 and No.5 (Table 1) specific to wild type allele. PCR amplification for wild-type allele was running at optimal conditions of $1.5 \mathrm{mM} \mathrm{MgCl}_{2}$ and $4 \mathrm{mM} \mathrm{MgCl}_{2}$ for mutant allele. The thermal cycling protocol included steps as initial denaturation at $95^{\circ} \mathrm{C}$ for 10 minutes, followed by 35 cycles of amplification: $95^{\circ} \mathrm{C}$ for $30 \mathrm{~s}, 64^{\circ} \mathrm{C}$ (for mutant allele) and $56^{\circ} \mathrm{C}$ (for wild-type allele) during $45 \mathrm{~s}$ and $72^{\circ} \mathrm{C}$ for $1 \mathrm{~min}$. The final extension was performed at $72^{\circ} \mathrm{C}$ for 10 minutes.

\section{Allele specific PCR to detect H1047R mutation in exon 20 PIK3CA gene}

The last type of PCR amplification was also performed in two separate tubes for wild-type and mutant allele. The first tube was containing primers No.6 and No.8 (Table 1) specific to 
mutant allele and the second tube was containing primers No.7 and No.9 (Table 1) specific to wild type allele. PCR amplification for both primer pairs was running at optimal conditions of $1.5 \mathrm{mM} \mathrm{MgCl}$. The thermal cycling protocol included steps as initial denaturation at $95^{\circ} \mathrm{C}$ for 10 minutes, followed by 35 cycles of amplification: $95^{\circ} \mathrm{C}$ for $30 \mathrm{~s}, 60^{\circ} \mathrm{C}$ (for both types of alelles) during $45 \mathrm{~s}$ and $72^{\circ} \mathrm{C}$ for $1 \mathrm{~min}$. The final extension was performed at $72^{\circ} \mathrm{C}$ for 10 minutes.

\section{RESULTS}

All of 60 tumors were analysed for "hotspot" PIK3CA mutations in exons 9 and 20. Three hotspots of PIK3CA gene were identified in pacients with breast cancer by AS-PCR. Overall, 8.3\% (5/60) of patients had E542K mutation (exon 9); 15\% (9/60) of patients were positive for E545K mutation (exon 9), (Figure 1 and 2 are showing AS-PCR detection of hotspots in exon 9) and 30\% (18/60) of patients had "hotspot" mutation in exon 20 (H1047R), (Figure 3). All results were verified by direct sequencing of PCR products (Figure 4) and we observed $100 \%$ agreement between those two methods.

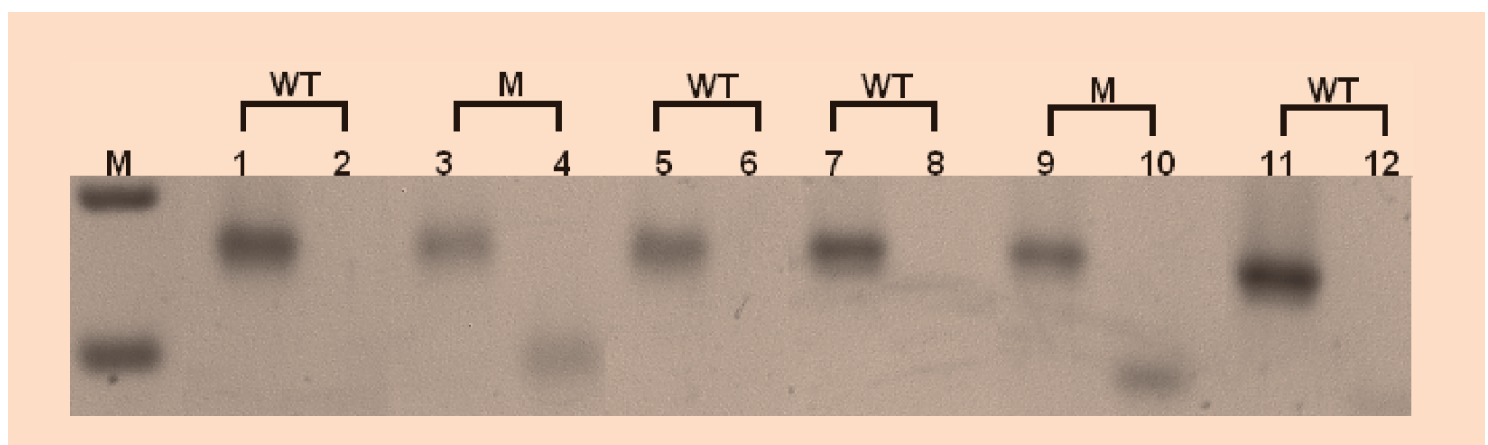

Fig. 1 AS-PCR analysis of hotspot mutations in exon 9 of PIK3CA gene. In lanes 1, 3, 5, 7, 9, 11 were used primers to wild-type allele and in lanes $2,4,6,8,10,12$ we used primers for detection of mutant allele in exon 9 (E542K). M represents 100bp marker.

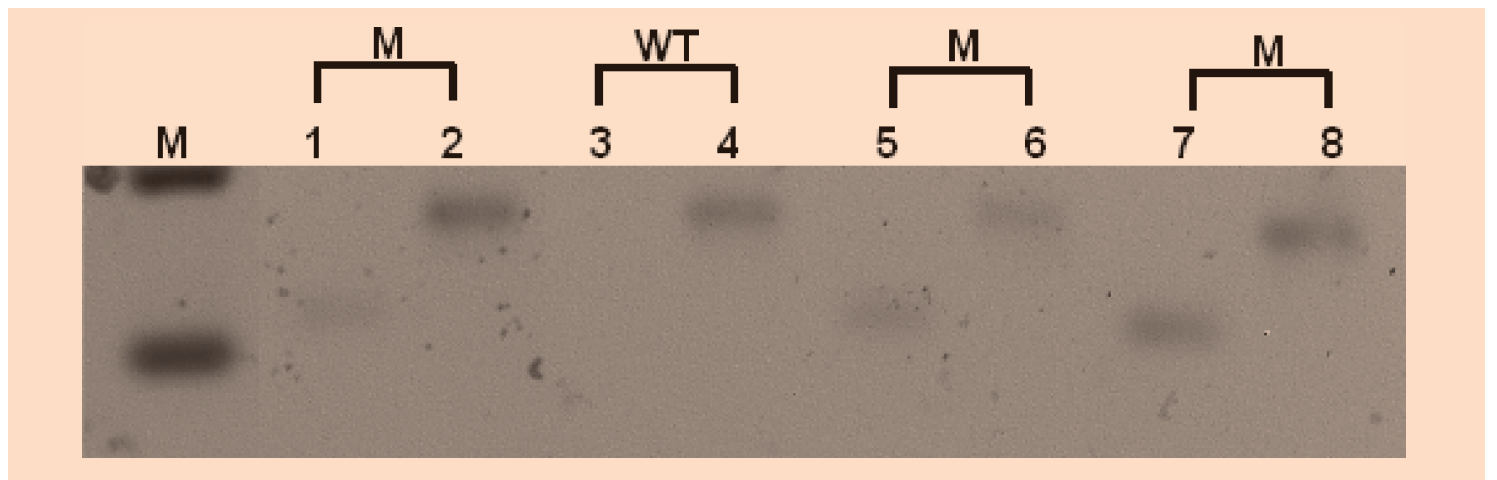

Fig. 2 AS-PCR analysis of hotspot mutations in exon 9 of PIK3CA gene. In lanes 1, 3, 5, 7 were used primers for detection of mutant allele in exon 9 (E545K) and in lanes 2, 4, 6, 8 we used primers for detection of wild-type alelle. $\mathrm{M}$ is $100 \mathrm{bp}$ marker. 


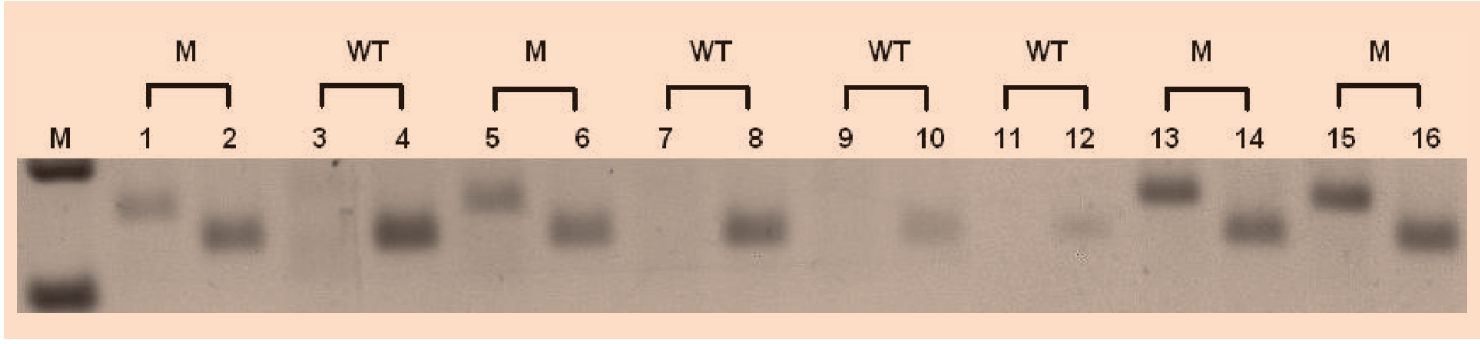

Fig. 3 AS-PCR analysis of exon 20. In lanes 1, 3, 5, 7, 9, 11, 13, 15 were used primers for detection of mutant allele in exon 20 (H1047R) and in lanes 2, 4, 6, 8, 10, 12, 14, 16 we used primers for wildtype allele. $\mathrm{M}$ is $100 \mathrm{bp}$ marker.
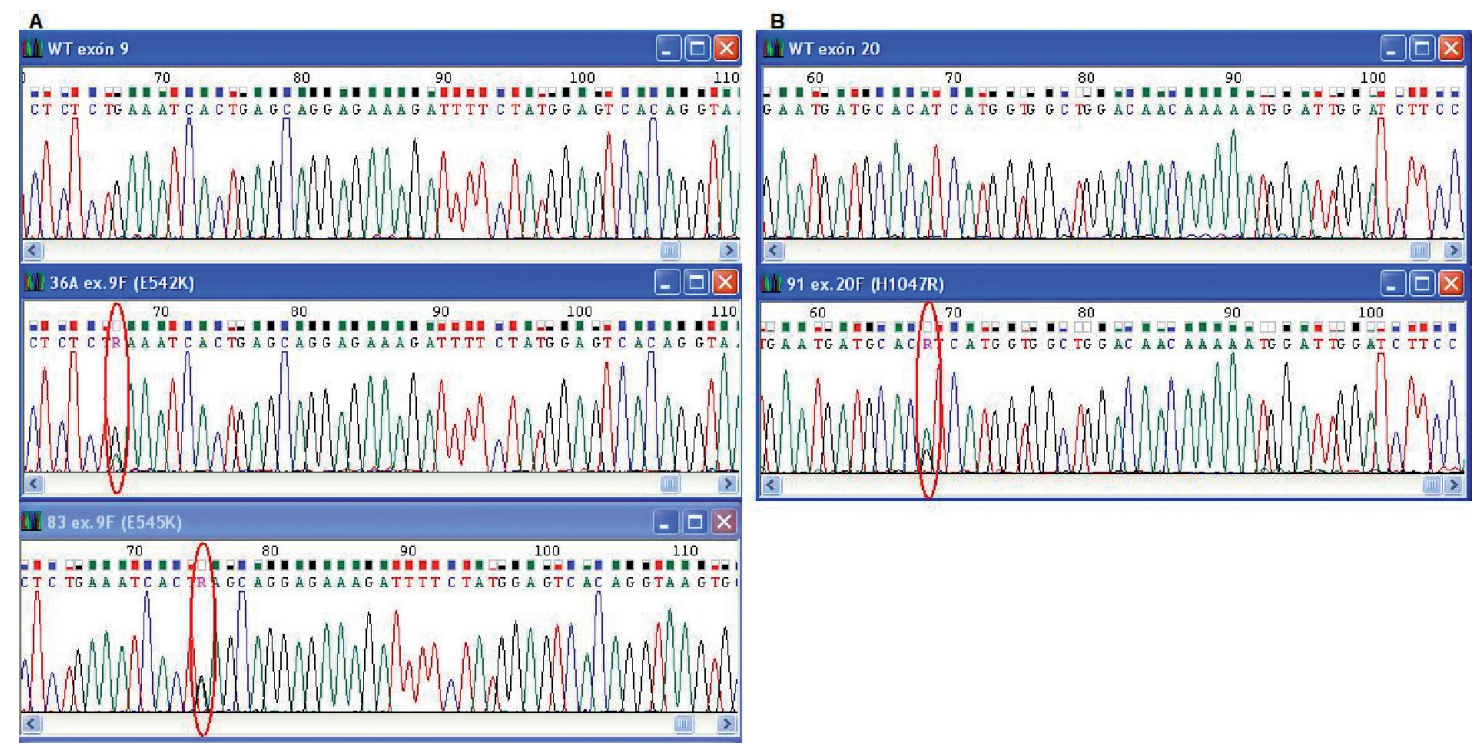

Fig. 4 Part A: electropherograms showing wild-type and hotspot mutations in exon 9 (E542K, E545K); Part B: electropherograms showing wild-type and hotspot mutation in exon 20 (H1047R).

\section{DISCUSSION}

PI3K was discovered by Lewis Cantley and his collegues (9). PIK3CA is gene coding the phosphatidylinositol-4,5-bisphosphate 3-kinase, catalytic subunit alpha and this gene is frequently altered in most of human cancers. PIK3CA mutations were common in endometrial (21\%), ovarian (17\%), colorectal (17\%), breast (14\%), cervical (13\%), and head and neck squamous cell cancer (9\%), (10). The majority of mutations occur at three hotspots: E542K, E545K in helical domain (exon 9) and H1047R in kinase domain (exon 20), (11). P110 carrying a hotspot mutation shows oncogenic activity; it can transform primary fibroblasts in culture, induce anchorage-independent growth and cause tumors in animals (2). The E542K and E545K mutations may confer a gain of function by disrupting an inhibitory interaction between p110 and p85 (12). The H1047R mutation may induce an allosteric change that mimics Ras-GTP binding, making this mutant independent of interaction with Ras-GTP (13). Both mutants are constitutively active, transform cells in culture, and pro- 
mote tumorigenicity in xenograft models. The role of the PI3K pathway in oncogenesis has been extensively studied in breast cancer. Several genetic aberrations, such as PIK3CA mutations, loss of PTEN, and AKT activation, make this pathway commonly activated in breast cancer. As a result, this pathway has become an attractive target for drug development (11). PIK3CA mutations have been found at similar frequencies in breast ductal carcinoma in situ (DCIS) lesions, DCIS adjacent to invasive ductal carcinoma (IDC), and IDC, suggesting that these mutations are early events in breast tumorigenesis and therefore may promote transformation of normal breast epithelial cells. The PI3K/Akt pathway is one of the most important signalling pathway in human carcinogenesis. Interestingly, PIK3CA amplification could aberrantly activate the PI3K/Akt signalling pathway. Inhibition of PI3K signalling can diminish cell proliferation, and in some circumstances, promote cell death. Consequently, components of this pathway present attractive targets for cancer therapeutics (14).

In summary, we have validated a sensitive assay for detection of three most common mutations in the PIK3CA gene in DNA extracted from paraffin-embedded tissue of breast cancer patients. All mutations determined by sequence analysis could be also recovered by allele-specific PCR assays.

\section{REFERENCES}

1. Wu G, Xing M, Mambo E.et al. Somatic mutation and gain of copy number of PIK3CA in human breast cancer. Breast Cancer Res 2005; 7(5):609-16.

2. Karakas B, Bachman KE, Park BH. Mutation of the PIK3CA oncogene in human cancers. Br J Cancer 2006; 94:455-9.

3. Di Cosimo S, Baselga J. Phosphoinositide 3-kinase mutations in breast cancer: a "good“ activating mutation? Clin Cancer Res 2009; 15(16):5017-9.

4. Cantley LC. The phosphoinositide 3-kinase pathway. Science 2002; 296:1655-7.

5. Samuels Y, Ericson K. Oncogenic PI3K and its role in cancer. Curr Opin Oncol 2006; 18:77-82.

6. Barbareschi M, Buttitta F, Felicioni L et al. Different prognostic roles of mutations in the helical and kinase domains of the PIK3CA gene in breast carcinomas. Clin Cancer Res 2007; 13:6064-9.

7. Little S. Amplification-refractory mutation system (ARMS) analysis of point mutations. Curr Protoc Hum Genet 2001; 7:9.8.1-9.8.12.

8. Darawi MN, Ai-Vyrn C, Ramasamy K et al. Allele-specific polymerase chain reaction for detection of Alzheimer $\mathrm{s}$ disease-related single nucleotide polymorphisms. BMC Med Genet 2013, 14:27.

9. Whitman KD, Kaplan DR, Schaffhausen B et al. Association of phosphatidylinositol kinase activity with polyoma middle-T competent for transformation. Nature 1985; 11(6016):239-42.

10. Janku F, Tsimberidou AM, Garrido-Laguna I et al. PIK3CA mutations in patients with advanced cancers treated with PI3K/AKT/mTOR axis inhibitors. Mol Cancer Ther 2011; 10(3):558-65.

11. Dumont AG, Dumont SN, Trent JC. The favourable impact of PIK3CA mutations on survival: an analysis of 2587 patients with breast cancer. Chin J Cancer 2012; 31(7):327-34.

12. Miled N, Yan Y, Hon WC et al. Mechanism of two classes of cancer mutations in the phosphoinositide 3-kinase catalytic subunit. Science 2007; 317(5835):239-42.

13. Zhao L, Vogt PK. Helical domain and kinase domain mutations in p110alpha of phosphatidylinositol 3-kinase induce gain of function by different mechanisms. Proc Natl Acad Sci USA 2008; 105(7):2652-7.

14. German S, Aslam HM, Saleem S, Raees A et al. Carcinogenesis of PIK3CA. Hered Cancer Clin Pract 2013; 11(1):5.

\section{Acknowledgement:}

This work was supported in part by projects: VEGA 1/0333/12 co-financed by Ministry of Education and project "Increase of career opportunities in research and development in the field of medical sciences“ ITMS code 26110230067 co-financed by EU funds.

Received: April, 22, 2014

Accepted: May, 23, 2014 